\title{
Transient Thermal and Structural Mechanics Investigation of the New Solid Tungsten Divertor Tile for Special Purposes at ASDEX Upgrade
}

\author{
Nikola Jaksic, Albrecht Herrmann, and Henri Greuner
}

\begin{abstract}
A new solid tungsten divertor for the fusion experiment axial symmetric divertor experiment upgrade is under construction at present. For special purposes of the plasma diagnostic in the divertor region, special formed solid tungsten divertor tiles are required. A so-called Langmuir probe is used to determine the ion temperature, ion density, and ion potential of the plasma. With the aim to place the probe on the right position, some of the divertor tiles (nine at the device circumference) have been adequately adapted. This paper discusses the main results of the numerical analysis of the thermomechanical behavior under heat load. Initially, the elastic-plastic calculation was applied to analyze thermal stress and the observed elastic and plastic deformation during the heat loading. The influence of a possible material degradation due to thermal cracking was studied. Additionally, the knowledge gained by the numerical analysis was used for the shape optimization of the divertor tile. The first results from the numerical life cycle analysis of the tungsten tiles are reported. Finally, based on the knowledge gained by the numerical analysis, in the light of problem complexity, it is recommended to perform some additional thermal tests. These tests should be performed with the aim to increase the reliability of the special-shaped tungsten tile during operation.
\end{abstract}

Index Terms-Axial symmetric divertor experiment (ASDEX) upgrade, divertor, fatigue, thermomechanical analysis, tungsten.

\section{INTRODUCTION}

A XIAL symmetric divertor experiment (ASDEX) upgrade (Fig. 1) is a midsize tokamak plasma fusion experiment [1]. Beginning in 1999, it was gradually transformed from a carbon to a tungsten f rst wall experiment by coating the graphite tiles with tungsten. Starting with the experimental campaign 2007, ASDEX was operated as a full tungsten experiment. More details about it can be found in [2]. The next step in the divertor improvement is the installation of a solid tungsten divertor made from powder metallurgy tungsten, to

Manuscript received July 31, 2013; revised February 19, 2014; accepted February 26, 2014. Date of publication May 16, 2014; date of current version June 6, 2014.

N. Jaksic is with the Integrated Technical Centre, Max Planck Institute for Plasma Physics, Garching 85748, Germany (e-mail: nikola.jaksic@ ipp.mpg.de).

A. Herrmann is with the E1 Department, Max Planck Institute for Plasma Physics, Garching 85748, Germany (e-mail: albrecht.herrmann@ipp.mpg.de).

H. Greuner is with the Material Science Department, Max Planck Institute for Plasma Physics, Garching 85748, Germany (e-mail: henri.greuner@ ipp.mpg.de).

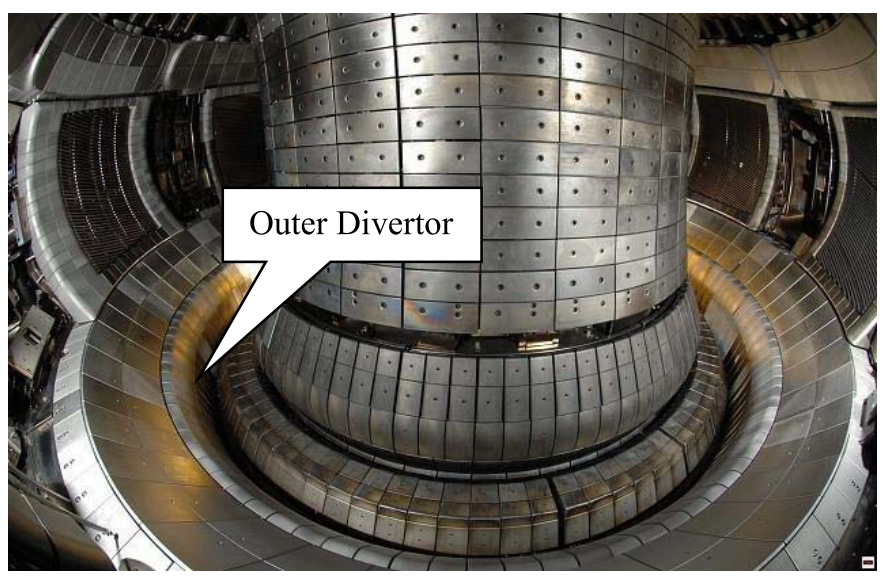

Fig. 1. Outer divertor of ASDEX upgrade.

increase the thermal performance of the current divertor tiles made of tungsten coated f ne grain graphite [3], [4].

The standard solid tungsten divertor tiles have been largely tested and numerically investigated already, which is described in detail in [5]. In addition to the standard tungsten tiles, special-shaped tungsten tiles with grooves and holes in the central part of the body are needed for the placement of flu $\mathrm{h}$ mounted Langmuir probes. This Langmuir tile requires some additional numerical investigations and tests, because it is subjected to the same thermal loads as the standard tiles. The investigations by means of $\mathrm{f}$ nite element method have been performed with a multiple nonlinear finit element model consisting of one divertor tile, thin interlayer made of f exible graphite, and divertor support structure, including the cooling pipe. The elastic-plastic material response constitutive law was used for the tungsten tile and contact surfaces were used for the geometrical separation of the model components. Effects of tungsten degradation due to recrystallization or grain growths at temperatures above $\sim 1300{ }^{\circ} \mathrm{C}$ were not considered since no reliable material data is available.

\section{Finite Element Model Description}

\section{A. General Description}

The assembly of the f nite element model according to the parts arrangement inside of the experimental facility is shown 


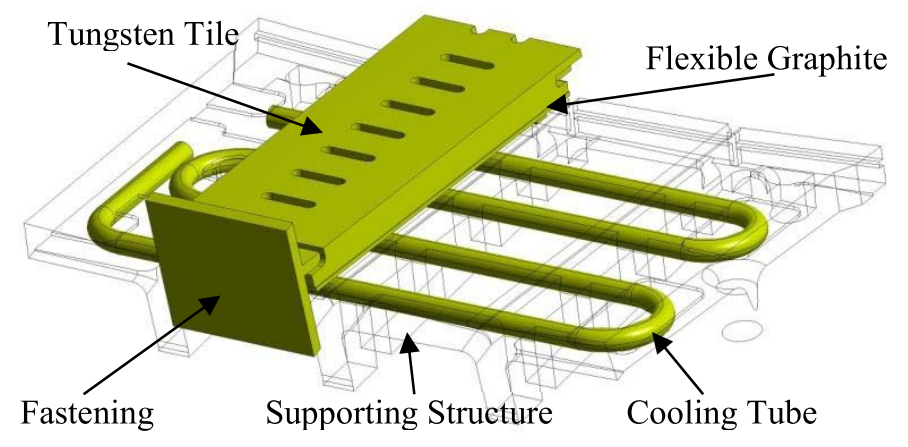

Fig. 2. Divertor tile for special purposes - assembly.

TABLE I

LOAD DEFINITION

\begin{tabular}{|c|c|c|c|}
\hline $\begin{array}{c}\text { Power } \\
\left.\text { [MW/m }^{2}\right]\end{array}$ & $\begin{array}{c}\text { Duration } \\
{[\mathbf{s}]}\end{array}$ & $\begin{array}{c}\text { Energy on Target } \\
{[\mathbf{k J}]}\end{array}$ & $\begin{array}{c}\text { Energy on Divertor } \\
{[\mathbf{M J}]}\end{array}$ \\
\hline 15 & 5 & 400 & 52 \\
\hline
\end{tabular}

in Fig. 2. The tungsten tile with the main dimensions of $250 \times 80 \times 15 \mathrm{~mm}^{3}$ is attached to the water-cooled support structure made of stainless steel by an appropriate fastening system. This fastening system is a clamping device with claws at both tile ends, which have a particular fl xibility to compensate the thermal dilatation without increasing the stresses in the tile body additionally. The fl xible graphite layer in-between serves as a compliant layer to improve the heat transfer. The model is multiple nonlinear, both in geometrical and material property law def nition. Between all single model parts, the contact surfaces with the coeff cient of friction (0.2) are defined The boundary conditions for thermal analysis have been define as follows: 1) all free surfaces have an outward radiation with an emissivity of 0.2 by an ambient temperature of $22{ }^{\circ} \mathrm{C}$ and 2) all contact surfaces have a heat transfer coeff cient of $2000 \mathrm{~W} / \mathrm{m}^{2} \mathrm{~K}$. These values have been taken f rstly from [6] and were additionally proved by the experiment. The $\mathrm{flm}$ convection coeff cient on the inner surface of the cooling tube is def ned with $10000 \mathrm{~W} / \mathrm{m}^{2} \mathrm{~K}$, which corresponds to the cooling water speed of $3 \mathrm{~m} / \mathrm{s}$.

\section{B. Loading Definition}

The tile loading chosen for the fi ite element analysis (FEA) corresponds to maximal thermal impact load during discharges in ASDEX upgrade, according to Table I.

The values in Table I are related to the power of one thermal pulse load and they are constant over the pulse duration. The ASDEX upgrade heat flu profil for one single tile can be approximated by a 2-D Gaussian function $f(x, y)$ according to

$$
f(x, y)=A \exp \left(-\left(\frac{\left(x-x_{0}\right)^{2}}{2 \sigma_{x}^{2}}+\frac{\left(y-y_{0}\right)^{2}}{2 \sigma_{y}^{2}}\right)\right)
$$

where $A$ is the maximal thermal impact load; $\sigma_{x}=70.0 \mathrm{~mm}$ and $\sigma_{y}=30.0 \mathrm{~mm}$ are the variance; $x_{0}=34.0 \mathrm{~mm}$ and $y_{0}=80.0 \mathrm{~mm}$ are the coordinates of the load peak at the target. Fig. 3 shows the heat $\mathrm{fl} \times$ pattern on the divertor tile

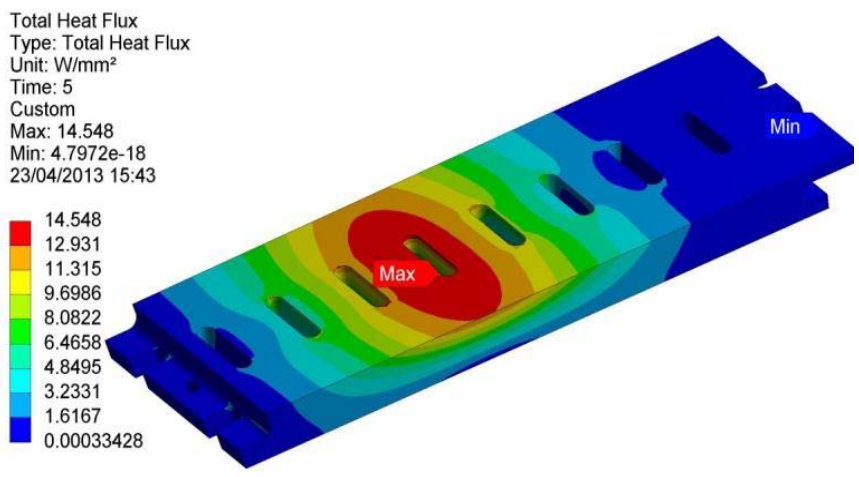

Fig. 3. Thermal impact load on Langmuir probes tile.

TABLE II

Tungsten-Main Material Properties

\begin{tabular}{|c|c|c|c|}
\hline Temp. [ $\left.^{\circ} \boldsymbol{C}\right]$ & $\begin{array}{c}\text { Yong's } \\
\text { Modulus } \\
{[\mathbf{G P a}]}\end{array}$ & $\begin{array}{c}\text { Thermal Expansion } \\
{\left[\boldsymbol{K}^{-1}\right]}\end{array}$ & $\begin{array}{c}\text { Thermal } \\
\text { Conductivity } \\
{\left[\boldsymbol{W m}^{-1} \boldsymbol{K}^{-1}\right]}\end{array}$ \\
\hline 200 & 396 & $4.5 \mathrm{E}^{-6}$ & 155 \\
\hline 400 & 393 & $4.5 \mathrm{E}^{-6}$ & 140 \\
\hline 600 & 387 & $4.6 \mathrm{E}^{-6}$ & 128 \\
\hline 800 & 379 & $4.8 \mathrm{E}^{-6}$ & 118 \\
\hline 1000 & 368 & $5.1 \mathrm{E}^{-6}$ & 110 \\
\hline 2000 & 285 & $5.6 \mathrm{E}^{-6}$ & 99 \\
\hline
\end{tabular}

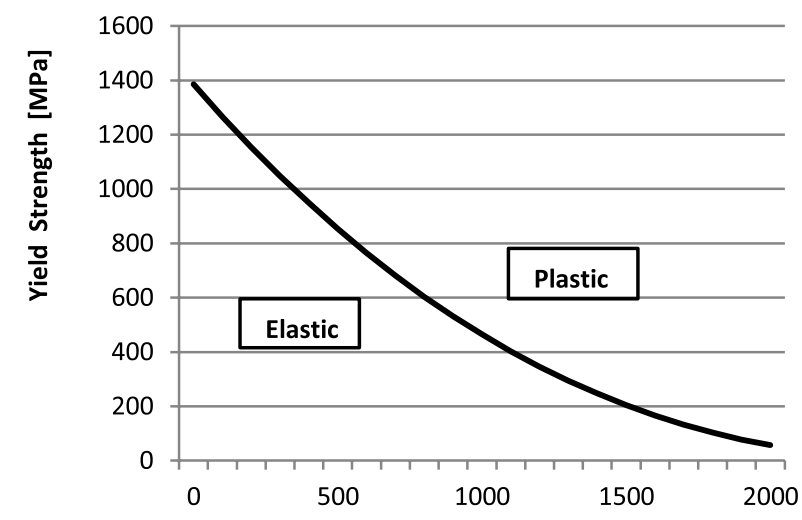

Temperature $\left[{ }^{\circ} \mathrm{C}\right]$

Fig. 4. Tungsten yield strength.

for Langmuir probes tile at the end of the load pulse of $5 \mathrm{~s}$, which corresponds to one discharge in ASDEX upgrade.

\section{Material Properties}

The nonlinear temperature-dependent material properties of tungsten [7], have been used in the analysis.

The elastic-plastic temperature-dependent material constitutive law for tungsten (Table II), define by multilinear isotropic hardening stress-strain curve have been applied. In addition, the temperature-dependent tungsten yield limit (Fig. 4) was used as well. 

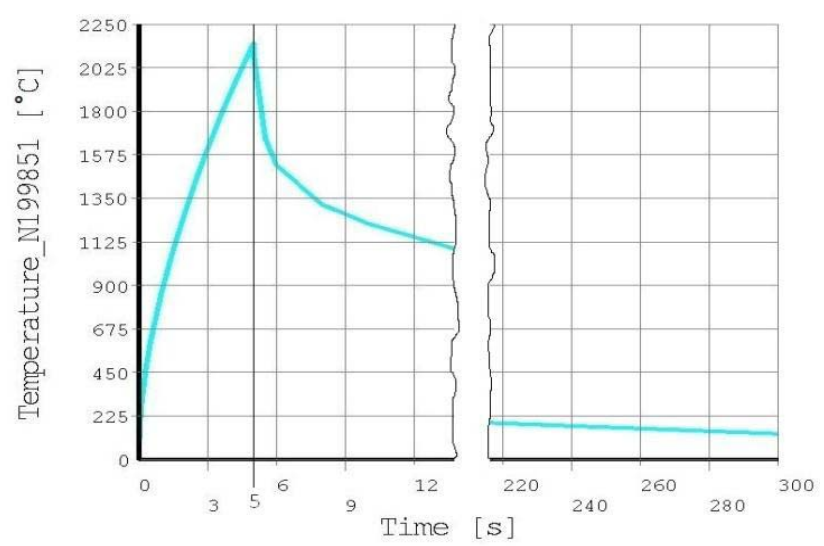

Fig. 5. Temperature in the course of time-hotspot region.

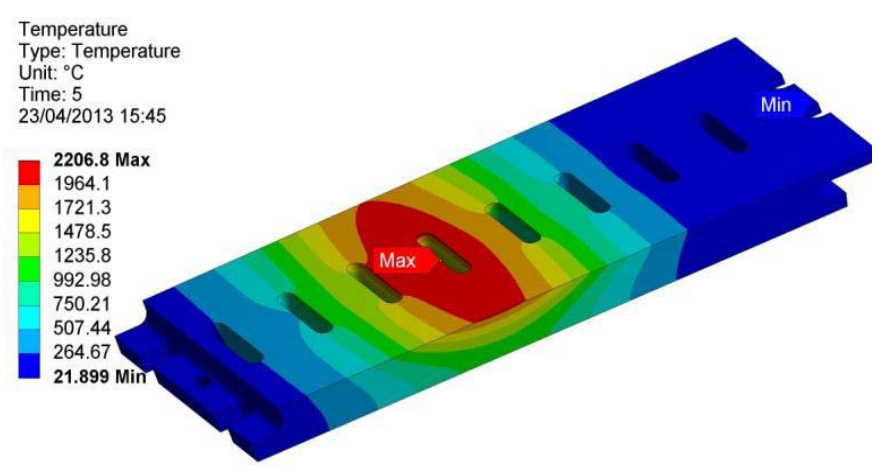

Fig. 6. Temperature pattern at the tile surface at peak load.

\section{RESULTS AND DISSCUSSION}

\section{A. Transient Thermal Analysis}

The f rst step in FEA was to simulate one whole load cycle, beginning with the heat load impact for duration of $5 \mathrm{~s}$ until cooling down of the tile before the next load cycle. A typical time-dependent temperature course for a point of the hotspot area is shown in Fig. 5. The maximal temperature of $\sim 2200^{\circ} \mathrm{C}$ occurs at the edge of the groove, placed near the load peak value. The tile temperature amounts after cooling down over the time of $300 \mathrm{~s} \sim 130{ }^{\circ} \mathrm{C}$, uniformly distributed over the whole body. The temperature pattern on the tile surface at the moment of reaching the surface maximal temperature at the end of the load impact is shown in Fig. 6. The results given by transient thermal analysis has been used as the input for the static structural analysis.

\section{B. Static Structural Analysis}

After the transient thermal analysis, the so-called coupled thermomechanical analysis has been performed. This analysis delivers stresses and strains, based on the temperature gradients given by transient thermal analysis. Fig. 7 illustrates maximal displacements of the whole structure occurring at the end of thermal load impact. The maximal displacement amounts $\sim 1 \mathrm{~mm}$ at the tile surface, facing the thermal load source. The maximal stresses in the tungsten tile can be

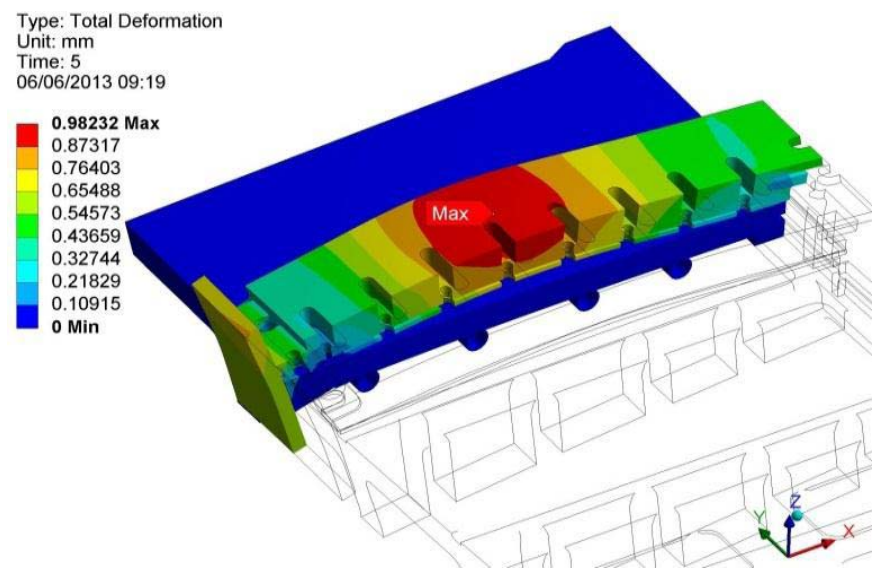

Fig. 7. Displacements magnitude of the whole assembly-cross-sectional view.

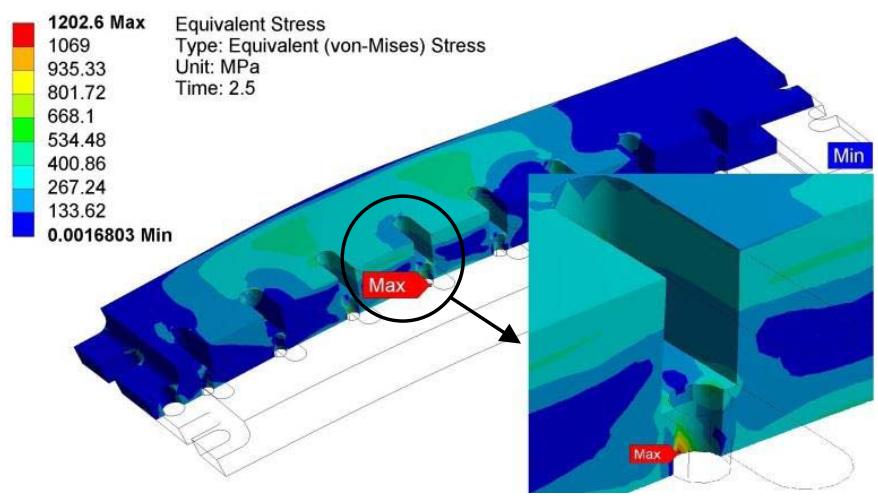

Fig. 8. Maximal Mises stress in tungsten tile-cross-sectional view.

def ned only for a certain point of time during the operation process.

In general, the strains and stresses are a function of temperature over the time according to the constitutive material law. The stress pattern over the entire body and the place with the stress maxima are changing continually during the whole test operation. Accordingly, the maximal Mises stress in the tungsten tile could be found at the analysis time of $2.5 \mathrm{~s}$, with the peak magnitude of $\sim 1200 \mathrm{MPa}$, located in the region of a hole edge at the tile bottom side (Fig. 8). Note that this stress level corresponds to the yield strength limit for a certain temperature and therefore the region concerned is being plastic deformed. Since the stresses in structure are changing their amount and place with time, the most suitable items for assessment of the structural part ability for the present class of problems are the permanent plastic strains and deformations in the tile body. Fig. 9 shows the equivalent plastic strain at the tile body after cooling down (300 s) for a single load case. The maximum strain of $\sim 0.0057$ occurs at the groove edge on the top body surface and at the surfaces of a hole at the tile bottom side. Due to the special shape of the Langmuir probes tile with grooves and holes in regions with the highest thermal loading is it in particular susceptible to the development of stress concentrations, which can lead to thermal crack initiation in a cyclic load operation. This fact leads to the degradation of material physical properties. 


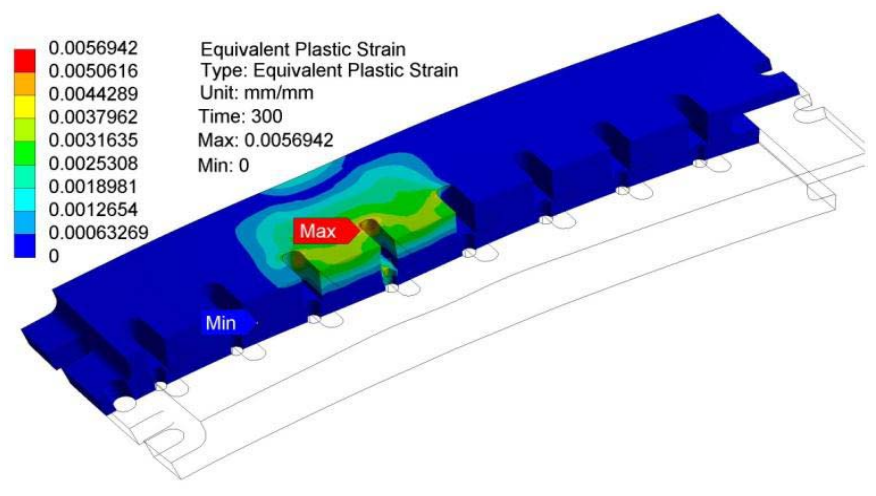

Fig. 9. Equivalent plastic strain in tungsten after $300 \mathrm{~s}-$ cross-sectional view.

Due to the plasma physics demands, the grooves and holes cannot be moved out of the thermal hotspot region, and consequently, some body shape optimizations are recommended. Accordingly, all edges and corners on the body should be shaped by radii, adequate to the general structural part function.

\section{Fatigue Assessment}

The plastic strains and the corresponding deformation of certain structural parts are the base for life cycle or fatigue evaluation in case of thermally driven stresses. Typically, for high temperature components and equipment, loaded by combined thermal and mechanical loading, where both the stresses and temperatures vary with time, the so-called thermal mechanical fatigue (TMF) analysis for fatigue assessment should be employed. The TMF damage occurs when a heated structure, which develops thermal gradients, is constraint in expansion. The expansion near places with stress concentration is often constrained by cooler material surrounding it. In this case, the thermal strains cause thermomechanical stress, which could induce fatigue damage in the structure. Moreover, there are two different types of TMF loading, so-called in-phase and out-of phase loading. The in-phase loading is the case, when the maximum temperature and strain occur at the same time. In case of the out-of-phase loading, a certain material region is under compression at the highest temperature and under tension at lower temperatures. In general, this type of loading is more likely to cause, aside from mechanical damage, also potential oxidation damage. Thereby, an oxide fil can form in compression at the higher temperature and then rupture during the subsequent low temperature tensile portion of the loading cycle, where the oxide fil is more brittle.

Commonly, the total damage in TMF case is the sum of three damage terms according to

$$
D=D_{\text {mech }}+D_{\text {ox }}+D_{\text {creep }}
$$

where $D_{\text {mech }}$ is the mechanical is damage; $D_{\text {ox }}$ is a potential oxidation damage; and $D_{\text {creep }}$ is the creep damage.

In our case, the inf uence of the oxidation damage and the creep damage at the fatigue are negligible due to the heating in a high vacuum environment and the general stress conditions in the tile body. Considering the loading conditions during

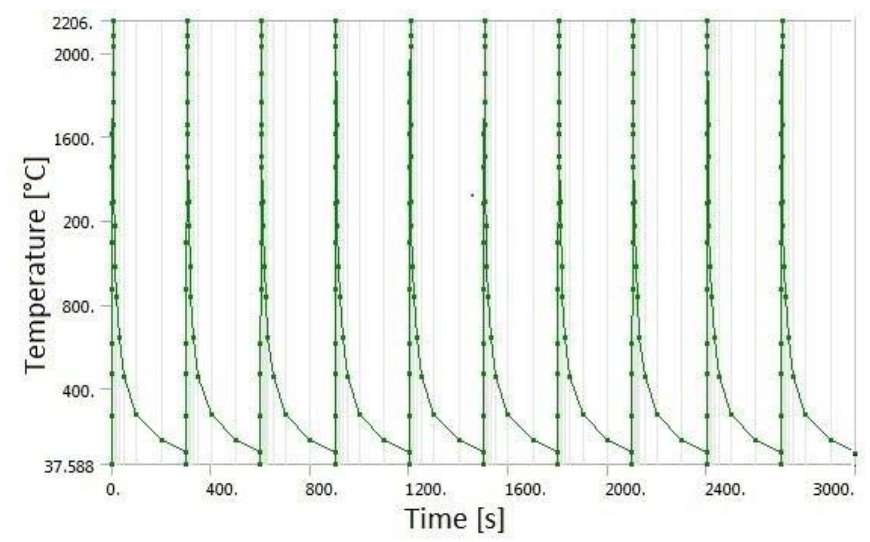

Fig. 10. Cyclic loading definit on-temperature in hotspot region.

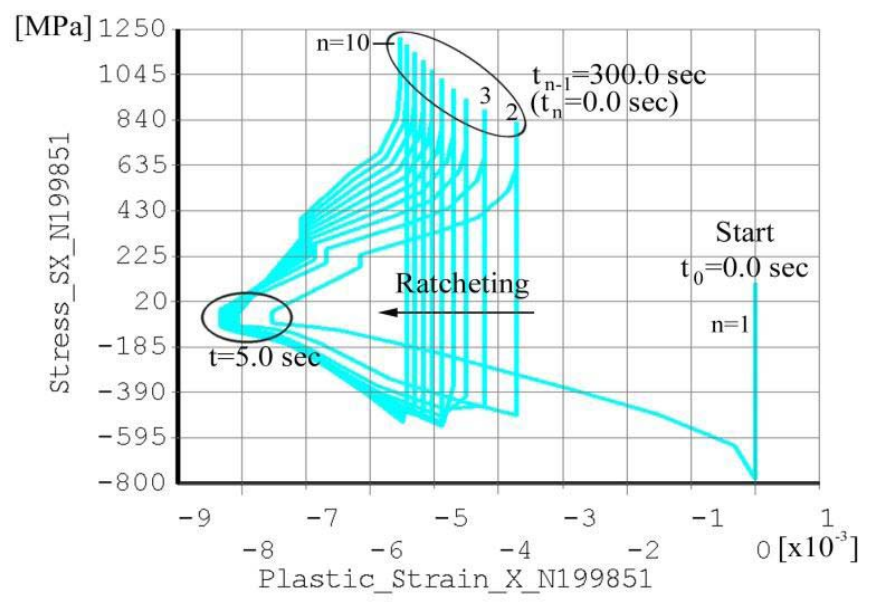

Fig. 11. Stress versa strain relationship for node 199851.

operation, only the mechanical damage has to be taken into account by life cycle assessment of the tungsten tile. The analysis presented in this paper is focused at the mechanical damage only, as the most dominated subject for the life cycle of the Langmuir probes tile.

1) Cyclic Load Analysis: First step in the TMF analysis was the cycle load analysis, including the frst 10 load cycles only (Fig. 10), because of the very large scope of the analysis. Distinctive stress versa strain relationship with the hysteresis loops formed by plastic cycling and the deviation owing to so- called ratcheting is shown in Fig. 11. The node numbered by 199851 is chosen as position for the stress-strain relationship evaluation. This node is located at the groove edge in the hotspot region near the max. label shown in Fig. 3. The stress used for the actual evaluation is the local $x$-component (direction, see Fig. 7), as dominant in this region and representative for the evaluation concerned. The index $n$ $(n=1,10)$ denotes the cycle number of the analysis. The time values in Fig. 11 refer to a single load cycle with the period of $300 \mathrm{~s}$. Accordingly, the time of $300 \mathrm{~s}$ for the cycle $n-1$ is concurrent to the time of $0.0 \mathrm{~s}$ for the cycle $n$. The time of the whole cyclic analysis with 10 cycles amounts consequently $3000 \mathrm{~s}$.

The hysteresis loops in Fig. 11 for the frst 10 load cycles show certain damage accumulation with the increasing values 


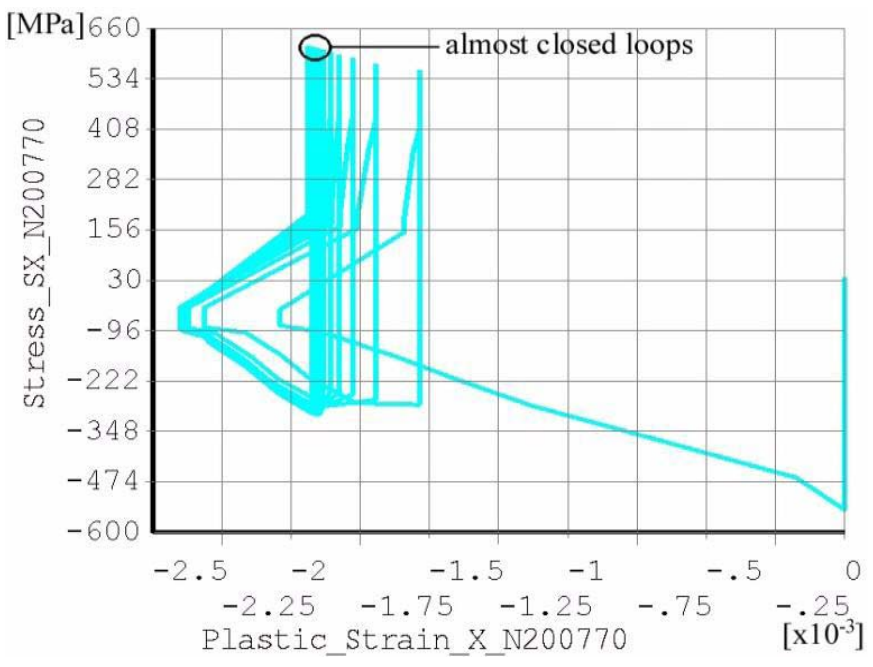

Fig. 12. Stress versa strain relationship for node 200770.

of the plasticity from 0.0057 after $300 \mathrm{~s}$ to the value of 0.0078 after $3000 \mathrm{~s}$. The residual stresses in the body are monotonously rising as well. Nevertheless, the comparison of the areas with plastic strains after fi st and last cyclic loading shows only a moderate increasing of the region concerned.

Furthermore, the hysteresis loops show a ratcheting effect with a monotonously increasing gradient. This material behavior indicates that the material tends to a closed loop of plastic deformation due to the shakedown effect.

Note that the plastic strain evaluation above is related to the hotspot region, only. The plastic strain evaluation, with the same entities, for the positions in the immediate proximity of the hotspot region shows higher shakedown effect. Accordingly, the hysteresis loops in Fig. 12 evaluated for the node 200770 , which is only $12 \mathrm{~mm}$ ( $y$-direction) distant from the hotspot node 199851, show nearly closed loops after six load cycles already. The residual stresses in this region are rising only moderately. Regarding the plastic deformations, it should be mentioned here that the region affected by plastic strains higher than 0.005 is comparatively small, entirely embedded in a purely elastic region.

This fact is the reason for the shakedown effect and thereby slows down the raising of residual stresses in the material.

2) Life Cycle Assessment: The fatigue assesment analysis has been done on the basis of results gained in the last load step of the cyclic load analysis. Considering the prior discussion and theoretical principles given in [9] and [10], the TMF assesment analysis has to be performed according to the so-called strain-life method. This method is primarily used for cases, which are characterized by higher thermally driven stresses, generally above the yield stresses, and plasic strain yielding. The method used for strain-life estimation based on the Manson-Coff $n-$ Morrow model is mathematically define by

$$
\frac{\Delta \varepsilon}{2}=\underbrace{\frac{\sigma_{f}}{E}\left(2 N_{f}\right)^{b}}_{\text {elastic }}+\underbrace{\varepsilon_{f}\left(2 N_{f}\right)^{c}}_{\text {plastic }}
$$

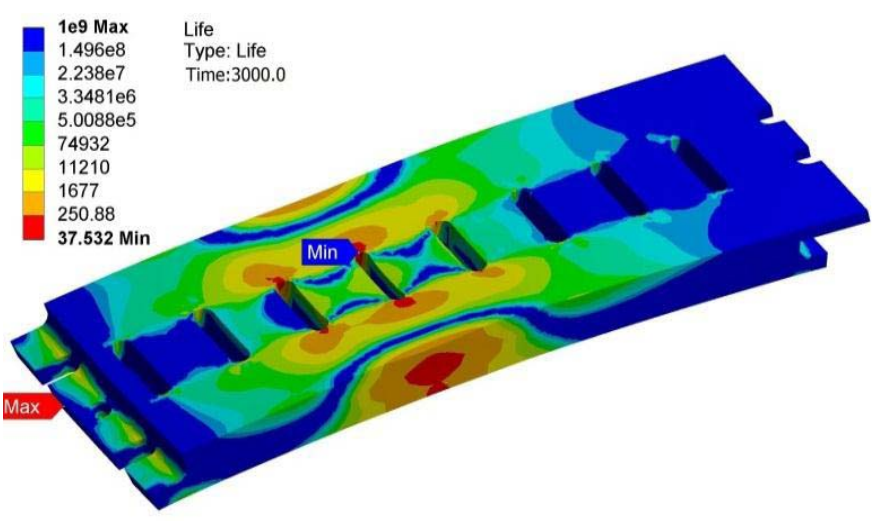

Fig. 13. Life cycle for tungsten tile.

where $N_{f}$ is the fatigue life; $\sigma_{f}$ is the fatigue strength coefficient $E$ is the modulus of elasticity; $b$ is the fatigue strength exponent; $\varepsilon_{f}$ is the fatigue ductility coefficie $\mathrm{t} ; c$ is the fatigue ductility exponent. This equation expresses the relationship between the total strain amplitude $(\Delta \varepsilon / 2)$ as a total of elastic and plastic parts, and the reversals to failure $\left(2 N_{f}\right)$, also known as method of characteristic slopes.

Owing to some diff culties by the evaluation of the total strain localized at the strain concentration region, a simplifi cation of (3) based on ftting of data from different metals can be carried out. The simplifie form according to [9], also known as universal slopes, is mathematically def ned by

$$
\Delta \varepsilon=\underbrace{3.5 \frac{\sigma_{f}}{E}\left(N_{f}\right)^{-0.12}}_{\text {elastic }}+\underbrace{\varepsilon_{f}^{0.6}\left(N_{f}\right)^{-0.6}}_{\text {plastic }} .
$$

The parameters required for a strain-life analysis according to [11] are: 1) $\sigma_{f}=200 \mathrm{MPa}$ is the fatigue strength failure; 2) $\varepsilon_{f}=0.1$ is the fatigue ductility coefficie $\mathrm{t}$; 3) $b=-0.12$ is the fatigue strength exponent (Basquin's exponent); and 4) $c=-0.6$ is the fatigue ductility exponent.

Note that the above listed values are taken from [7], [8], and [12] or were evaluated according to [13], on the basis of static test values. The infl ence of the operational temperature level on material properties has been taken into account as well. Fig. 13 shows a contour plot of the numerical fatigue life evaluation for the tungsten tile structural part. Under the assumptions made by load conditions and fatigue material properties, in a frst approach it can be generally said, that the structural part will not fail before 37 load cycles at least. This life cycle number in correlation with the value for regular tungsten tile [2] (without grooves and holes) of $\sim 1000$ load cycles, under very similar thermal loading, shows the inf uence of the body shape features at the life cycle of the structural part.

A purely numerical life cycle degradation factor amounts 27 in this comparison case. Nevertheless, the areas at the structural parts affected by the minimal life cycle mentioned above are very different. The area concerned in case of regular tungsten tile is quite large and extended over the whole tile cross section and hence should be fully considered.

In case of the tungsten tile for special purposes, the area concerned is very small (Fig. 13), conf ned to groove 
edge only. Consequently, the numerical estimated life cycle value will not implicitly cause the total failure of the structural part after 37 load cycles. This value indicates the probable number of load cycles until the frst crack incitation at the region concerned. According to the prior discussion, the crack propagation seems to come to rest, owing to the shakedown effect.

\section{CONCLUSION}

A comprehensive thermomechanical analysis of the new solid tungsten divertor tile for special purposes at ASDEX upgrade has been performed. After the transient thermal analysis, the so-called coupled thermomechanical analysis followed by the life cycle assessment analysis, have been performed.

Owing to the special shape of the Langmuir probes tile with grooves and holes in regions with the highest thermal loading is it in particular susceptible to the development of stress concentrations. This can lead to crack initiation in a thermal cyclic load operation and thereby to the degradation of material physical properties. Due to the plasma physics demands, the grooves and holes cannot be moved out of the thermal hotspot region, and consequently, some body shape optimizations are recommended. Accordingly, all edges and corners on the body should be shaped by radii, adequate to the general structural part function.

The life cycle assessment analysis shows signifi ant life cycle degradation at the strain concentration region, compared with the tungsten tile with the regular body shape. Nevertheless, the material properties characterized by higher ductility at higher temperature will most likely conf ne the possible crack propagation, owing to the shakedown effect.

Finally, based on the knowledge gained by the numerical analysis, in the light of problem complexity and possible inf uence of recrystallization effect for tungsten temperatures above $1300^{\circ} \mathrm{C}$, it is recommended to perform some additional thermal tests. These tests should be performed with the aim to increase the reliability of the special-shaped tungsten tile during operation.

\section{ACKNOWLEDGMENT}

The authors would like to thank J. Tretter for his valuable discussions and comments. The authors would also like to thank S. Vorbrugg and B. Böswirth for their help during the preparation of this paper.

\section{REFERENCES}

[1] A. Herrmann and O. Gruber, "ASDEX upgrade-Introduction and overview," Fusion Sci. Technol., vol. 44, no. 3, pp. 569-577, Nov. 2003.

[2] R. Neu et al., "Plasma wall interaction and its implocation in an all tungsten divertor tokamak," Plasma Phys. Controlled Fusion, vol. 49, no. 12B, pp. 59-70, 2007.

[3] A. Herrmann et al., Physica Scripta, T144 (2011) 014068.

[4] A. Herrmann et al. (2012). Design and Concept Validation of the New Solid Tungsten Divertor for ASDEX Upgrade (SOFT) [Online]. Available: http://dx.doi.org/10.1016/j.fusengdes.2013.03.007

[5] N. Jaksic, H. Greuner, and A. Herrmann, "FEM investigation and thermo-mechanical tests of the new solid tungsten divertor tile for ASDEX upgrade," Tech. Program SOFE, vol. 88, nos. 9-10, pp. 1-3, 2012.
[6] C. J. Geankoplis, Transport Processes and Unit Operations, 3rd ed. Englewood Cliffs, NJ, USA: Prentice-Hall, Mar. 1993.

[7] ITER Material Properties Handbook, ITRS, Denver, CO, USA, 2001.

[8] Tungsten-Material Properties and Applications, Plansee Group, Tyrol, Austria, 2000

[9] S. S. Manson and G. Halford, A Method of Estimating High Temperature Low Cycle Fatigue Behaviour of Materials. Cleveland, OH, USA: Lewis Res. Center, Jun. 1967.

[10] J. Morrow, Cyclic Plastic Strain Energy and Fatigue of Metals. Philadelphia, PA, USA: ASTM, 1965, pp. 45-83.

[11] Theory Reference, ANSYS Inc., Canonsburg, PA, USA, Nov. 2011.

[12] P. Mertens et al., Bulk Tungsten in the JET Divertor: Potential Influence of the Exhaustion of Ductility and Grain Growth on the Lifetime. Alexandria, VA, USA: JET-EFDA, May 2012.

[13] The Designer's Guide to Tungsten Carbide. Greensburg, PA, USA: General Carbide, 2007.

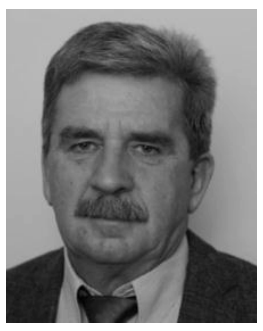

Nikola Jaksic was born in Karlovac, Croatia. He received the Dipl.Ing. (M.Sc.) degree in mechanical science and engineering from the Faculty of Mechanical Engineering and Naval Architecture, University of Zagreb, Zagreb, Croatia, in 1981.

He was a Development Engineer with the Research and Development Department, Jugoturbina, Karlovac, Croatia, from 1981 to 1987 , for steam turbines for power plants. During this time, he spent two years at BBC, Baden, Switzerland, specializing in steam turbines for nuclear power plants in the frame of a technology transfer agreement. Since 1987, he has been a Scientist/Analyst with the Max Planck Institute for Plasma Physics, Garching, Germany. He was responsible for conceptual design, development, and structural analysis of the support structure for superconducting coils of the plasma fusion experimental device Wendelstein 7-X. His current research interests include multif eld analysis of the solid tungsten divertor needed in plasma fusion science.

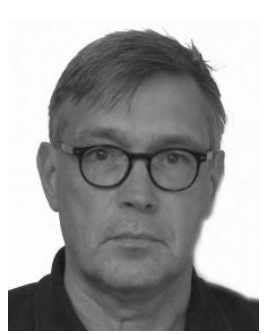

Albrecht Herrmann was born in Berlin, Germany. $\mathrm{He}$ received the Diploma and Ph.D. degrees in physics from the Technical University of Dresden, Dresden, Germany, and the Humboldt University of Berlin, Berlin, Germany, in 1984 and 1988, respectively.

He was a Research Scientist in surface science and plasma wall interaction from 1984 to 1991. In 1992, he was a Senior Scientist for power and particle exhaust with the Max Planck Institute for Plasma Physics, Garching, Germany. In 2006, he was the Group Head for maintenance and enhancement of the ASDEX Upgrade experiment and Deputy Leader of the ASDEX Upgrade project. He is the co-author of two textbooks, Guest Editor of a journal, fir $\mathrm{t}$ author of more than 20 articles, and leading author of more than 40 articles.

Henri Greuner received the Diploma degree in mechanical science and engineering from the Technical University of Dresden, Dresden, Germany, in 1983 .

He was with the Max Planck Institute for Plasma Physics (IPP), Garching, Germany, in 1993, and was responsible for the development and design of the plasma-facing components of the stellarator Wendelstein 7-X. Since 2001, he has been strongly involved in the development and high-heat flu testing of plasma-facing materials and components, and is responsible for the operation of the high heat $\mathrm{f} u x$ test facility GLADIS at IPP. 